\title{
Learning from web information seeking studies: some suggestions for LIS practitioners
}

\author{
Ina Fourie
}

Ina Fourie, Department of Information Science, University of Pretoria, Pretoria, South Africa

Purpose - To explore the value of web information-seeking studies for practice, and to bring selected research findings and their potential to the attention of library and information science (LIS) practitioners.

Design/methodology/approach - Based on a selective literature review of web information-seeking studies to highlight findings considered most relevant to LIS practitioners. A fairly extensive, but not exhaustive, list of sources was identified. Reasons for the gap between web information-seeking theory in the form of research reports and LIS praxis are briefly considered.

Findings - The value of web information-seeking studies is limited to theoretical and methodological growth if they do not also affect practice. Suggestions are offered on a selection of aspects of how LIS practitioners can incorporate findings from web information-seeking studies. These include improved self-knowledge and self-efficacy of practitioners and users, adapted approaches to information literacy and user empowerment programmes, improved access to the full spectrum of the information infrastructure, a stronger emphasis on the link between information-seeking and information use and knowledge generation, and involvement in pragmatic small-scale research.

Research limitations/implications - Although the scope of findings discussed is limited to a selection considered most important by the author, this could be supplemented by further reviews to allow for new findings and insights into practical implications.

Practical implications - Should stimulate LIS practitioners' interest in the results of web information-seeking studies and their value for praxis.

Originality/value - Although all research papers are concluded with recommendations etc., a similar literature review with specific guidelines for practitioners has not been published in the LIS subject literature. 


\section{Introduction}

Since earlier reports by Fourie (2002), Hsieh-Yee (2001) and Jansen and Pooch (2001) there has been a remarkable growth in studies of web information-seeking behaviour. Recent articles stressing the importance of web studies include Nicholas et al. (2004), Ozmutlu et al. (2004), Pharo and Järvelin (2004), Spink et al. (2004) and Whitmere (2004). Two recent editions of the Journal of the American Society for Information Science and Technology are dedicated to information seeking (Spink and Cole, 2004). Information seeking is considered a complex, dynamic, social human behaviour that needs as rich a picture as possible to truly understand the phenomenon - and even then there will be many unanswered questions. web information-seeking studies claim to be able to assist in knowledge representation, the design of web sites, portals, training, and web-based information retrieval systems (IRS), online education, electronic customer relationship management (CRM) and electronic service quality.

Research projects can help to build theoretical frameworks, but a more definite effort should also be made to apply findings in practice. In the light of complaints often raised that there is a gap between information retrieval (IR) theory and practice, this article intends to offer some suggestions to library and information service (LIS) practitioners (especially those involved in information literacy programmes and acting as intermediaries on behalf of users) on how to apply research findings from web information-seeking studies (a narrower facet of IR). According to Hancock-Beaulieu, as cited by Ellis (1989, p. vii):

The dissemination of research findings in information and library studies, as with other fields of study, has not traditionally been aimed at the practitioner or the uninitiated student. Yet the need to bridge the gap between research and application, between theory and practice, could in part be achieved by improving communication within the profession.

In line with Wilson's nested model, studies of web information-seeking behaviour include information searching and information retrieval as part of the umbrella concept of information behaviour. According to Wilson (1999b, p. 263), information seeking and information behaviour belong to the broader field of user studies. He explains:

Information behaviour may be defined as the more general field of investigation ... with information-seeking behaviour being seen as a sub-set of the field, particularly concerned with the variety of methods people employ to discover, and gain access to information resources, and information-searching behaviour being defined as a sub-set of information seeking, particularly concerned with the interactions between information user (with or without an intermediary) and computer-based information systems, of which information retrieval systems for textual data may be seen as one type.

This article will use an ad hoc selection of findings from the subject literature to stimulate practical use of these research findings. More detail on research trends and theoretical models can be found in Jansen and Pooch (2001), Hsieh-Yee (2001) and 
Fourie (2002, 2004). The selection of findings is based on the author's perception of what might currently be of importance.

\section{Bridging the gap between theory and praxis: a challenge}

Web information seeking studies are mostly reported in academic journals such as the Journal of the American Society for Information Science and Technology, Journal of Documentation, and Information Processing and Management. Articles also appear more sporadically in Online Information Review, The Electronic Library, Information Research and First Monday. With the exception of the last two, these journals are not necessarily available to practitioners in public or special LIS. Those working in academic LIS at institutions with LIS teaching departments may, however, have access to such journals. Most research findings are also reported at more academically oriented conferences such as the annual conference of the American Society for Information Science and Technology (ASIS\&T). Apart from inadequate access to the literature, there are also other factors keeping practitioners from incorporating the findings from web information-seeking studies into their practice. The following are a few of these factors:

- Highly academic language and style of the research articles and conference papers. Ellis (1989, p. viii) aptly cites a student from an Information Management Master's class: "In some respects contemporary information retrieval research comprises a plethora of different approaches and techniques, each with its own adherents and opponents, experts and neophytes. The first encounter with the literature can be baffling and confusing."

- Lack of explicit guidelines on the implementation of research findings in practice. Bilal (2000, 2001, 2002) and Choo et al. (1999, 2000a, 2000b, 2000c) are exceptions. It is suggested that researchers offer explicit guidelines on how their research findings can change practice, and preferably through forums accessible to practitioners. The author will attempt to offer a few such suggestions in this article.

- Inadequate communication between researchers and practitioners. Many useful research findings are often difficult, but not impossible, to implement in practice if taking a pragmatic viewpoint. Closer cooperation between researchers and practitioners might improve understanding and support for the viewpoints of both. It might also help if researchers became involved with practical implementation.

- Inadequate support for LIS practitioners on how to move from noting research findings to application and adaptation according to their own situation in practice. Workshops on how to change and reconsider practices might be useful.

The suggestions for implementation will be discussed according to the following broad categories considered relevant for practitioners:

- $\quad$ self-understanding and self-efficacy; 
- information literacy programmes;

- information-seeking infrastructures;

- linkage between information-seeking and information use and knowledge generation; and

- pragmatic small-scale research.

\section{Self-understanding and self-efficacy}

Early IR research followed a systems approach that focused on recall and precision measures to evaluate the success of information retrieval. Online searches also had to be extremely well planned and make allowance for all possibilities (e.g. retrieving too much, too little, no, or irrelevant or partly relevant information). The emphasis was on the correct use of system techniques, choice of search terms and advanced search and database features as well as cost-effective searching. Although possible, really interactive searching was limited due to the high cost of commercial online services such as Dialog. Although it was acknowledged that personal traits and subject expertise are important determinants of successful online searching, the emphasis was strongly on knowledge of the system and database features (i.e. optimisation of the system features).

Although understanding the web in terms of the systems approach is still very important, other ways of considering IR and web information seeking should also be considered. Ingwersen (1992, 1996) proposes a cognitive model that considers the user's (or information seeker's) cognitive space, social and organizational environment and the role of the intermediary and author. He explores this approach further in Ingwersen (1999).

People's knowledge of a topic, the search system (e.g. database or search engine), search experience et cetera are important determinants in the search process. It is important that LIS practitioners should understand their own grasp and perception (cognitive frameworks) of information seeking, the subjects or topics, information needs, and purpose of information seeking, how these will influence how they search on behalf of others, and how they will train and advise users. They should also understand how these factors will impact on the success of the search. There is more to information seeking than making a calculated guess about the most "perfect" search strategy. Cognitive frameworks are, however, never static and should change and develop over time. In fact, proactive change towards a better understanding should be encouraged. LIS practitioners who are aware of this might find it easier to share their experiences and growth towards successful information seeking as well as failures with users. If one is aware of the shortcomings of your cognitive framework (i.e. the things you do not know or do not fully understand at a particular point), it might also be easier to identify appropriate intervening measures (e.g. using browsing techniques or placing more emphasis on adapting search strategies according to new insights or relevance judgments), or calling on an intermediary's advice. Users should be encouraged to consider ways in which they can learn more about a system (e.g. applying different techniques to a real-life information problem), or learning more about a topic (e.g. finding a key document on the 
topic by searching according to a specific author or title, or doing a broad search in the title field).

Apart from knowledge (cognitive aspects), LIS practitioners also need to understand their emotions and especially the emotions that users might experience. It is quite normal to feel anxious, frustrated, nervous or desperate: novices are not the only ones to experience such feelings. Affective facets of information seeking are explored by Kuhlthau (1991, 1993, 1994), and are addressed in more detail in a following section. Users' feelings during the process of information seeking may also affect their perceptions of selfefficacy (explained in following paragraphs). LIS practitioners should, therefore, be more alert to affective aspects, and share their own feelings of inadequacy with users. They should also explain that negative feelings often disappear once the information seeker seems to be successful.

Heinström (2000), Limberg (1999), Ford et al. (2002a, b, 2003) amongst others have found that personality types and learning styles will influence information-seeking styles. Limberg (1999) argues that learning style and personality can influence the following: relevance judgments, document selection criteria, ways of dealing with information overload, thoroughness in information seeking and decisions to terminate a search, critical information judgment, ways of dealing with bias, search strategies, use of information sources and the effort invested in seeking information

Heinström (2000) distinguishes a number of learning styles. According to him, “deep divers", for example, dive deeply into the information flow, go for depth and quality in choosing information sources and relate best to a deep study approach. In 1991 Cline as quoted by Kerka (1998) envisioned a day when we would carry cards coded with our learning style information and individual profiles that we would plug into a machine that would adapt itself to our preferred style. Until that day comes it might be useful for LIS practitioners and users to take note of how their personality and learning styles affect their styles of information seeking and success rates. It might also make it easier for them to understand search decisions (e.g. to terminate a search, or to follow a different route), and for LIS practitioners to explore differences between users' information-seeking behaviour. So much for self-understanding; we now look at how self-efficacy influences our information-seeking behaviour.

Alberto Bandura introduced the concept of self-efficacy as the belief that one can successfully execute the behaviour required to produce the desired outcomes in 1977. Waldman (2003) considers the correlation between self-efficacy and the use of library electronic resources, while Wilson (1981) also mentions self-efficacy as an influence in information seeking. Research on self-efficacy and information seeking is reported by Nahl and Tenopir (1996) and Ren (2000). Nahl and Tenopir (1996) found that higher self-efficacy translated into higher search efficiency, success and satisfaction. In a study of library instruction and self-efficacy, Ren (2000) showed a positive correlation between students' self-efficacy and frequency of use of electronic library resources. 
Individuals come by their self-efficacy beliefs in several ways, for example by interpreting what they have done. Successful outcomes raise self-efficacy, while it is lowered by failures. Users can, for instance, be shown step-by-step how to solve real-life problems they are experiencing because of the particular approach they are following. People also develop self-efficacy beliefs through “vicarious experiences”, for example by observing others (e.g. intermediaries or peers) who have dealt with certain experiences, and then inferring how they would handle a similar experience (Waldman, 2003). This can be achieved through demonstrating a selection of real-life problems from the user's point of view, showing where he/she might start and how he/she can move from there to exploring the result and thus towards more successful searches. We need to move away from the idea that people with inadequate search and subject skills should be able to formulate a "perfect" first strategy. Apart from correctly applying search techniques and search features, users should rather be encouraged to grow in their search strategies, to learn and to explore different options - in as calculated a way as possible.

Self-efficacy beliefs also develop through "verbal persuasions", or when someone expresses his/her confidence that a person will be able to succeed. Self-efficacy beliefs will determine how long an individual persists in information seeking, and in fact whether he/she will engage in the task at all. When self-efficacy beliefs are low, different strategies should be followed to encourage users to successfully complete information seeking (Waldman, 2003). Knowledge of search techniques and system features can be enhanced through interactive, online drill and practice exercises to help users develop more confidence in this aspect of information seeking.

\section{Information literacy programmes}

Many excellent articles have been published on information literacy programmes. Based on web information-seeking studies, the following types of programme seem to deserve more attention:

- Preparation of information literacy programmes for a variety of target groups based on reported research findings.

- Acknowledging the complexity of information needs and the difficulties in fully understanding them.

- Exploring the interactive and iterative nature of information seeking.

- Exploring the power of different types of information searching.

- Dealing with affective aspects of information-seeking behaviour.

- Acknowledging and dealing with barriers to successful information seeking.

The above-mentioned are only a few suggested in the research literature; there are many more. 


\section{Preparing information literacy programmes for a variety of target groups}

Information seeking has been studied in all walks of life, including everyday life information seeking (ELIS). The target groups are very diverse, including children (Bilal, 2000, 2001, 2002; Bilal and Kirby, 2002; Cooper, 2002), elderly people (Burwell, 2001), and ordinary citizens seeking information for daily needs (Carey et al. 2001; Chatman, 1991; Cool et al., 1996; Pettigrew et al., 2002; Savolainen, 1995; Spink and Cole, 2001). The first step in planning information literacy and user empowerment programmes should be to note the information needs and information-seeking behaviour of a specific group as reported in the subject literature.

Information on a specific target group should also be collected through formal interviews, focus group interviews, and transaction log analysis. The latter can be collected through web browsers or special transaction log software such as Lotus ScreenCam (www.lotus.com/home.nsf/welcome/screencam) or Activity Monitor (www.softactivity.com). The value of informal conversations with LIS patrons should also not be underestimated. Ongoing efforts should be made to learn more about the users: they live in a dynamic, rapidly changing world, with ongoing changes in pressures and expectations. Their vocabulary, interaction with systems and each other, and access to information are rapidly changing. The same applies to their cognitive structures and ability to analyse their information needs. The collection of data on target groups should therefore not be a once-off activity.

ELIS appears to be of growing importance (as reported by Spink and Cole (2001) and Savolainen (1995), for example). Public librarians in particular should therefore prepare themselves to deal with this, and especially with the increase in the demand for healthrelated information.

Collaborative information seeking also seems to be of growing importance (e.g. Hansen and Järvelin, 2005; Hyldegård, 2004; Lee, 2005).

\section{Acknowledging the complexity of information needs and the difficulties in fully understanding them}

Most information literacy programmes start by explaining that an information need must be analysed to identify search concepts and then search terms. They certainly all mention that this can be difficult. However, the question is whether they really explain the complexity of analysing an information need in such a way that users understand exactly how difficult it can be, and that this is often the most difficult task, even for experienced intermediaries.

Many authors have attempted to explain information needs: 
- Dervin and Nilan (1986) and Dervin (1999) follow a sense-making approach. Users need information to make sense of a particular problem situation. She distinguishes four components: a situation, bridge, gap and the outcome. To make sense of a situation, the gap must be identified, and steps taken to bridge the gap. What do you for example need to know to deal with cancer? Nutritional information, or information on coping skills, care-giving, the prognosis of the particular cancer or information on the treatment? If we consider "sense-making" in other contexts, say making sense of a relationship, the complexity of "sensemaking” becomes so much clearer.

- Belkin et al. (1982a, b) developed the notion of an anomalous state of knowledge (ASK) that needs to be fulfilled: users realize that there is a gap between what they know and what they need to know. This is, however, easier said than done.

- According to Wilson (1981) information needs are secondary needs to other needs such as physiological, cognitive and affective basic needs, which means that the user actually also needs to understand both the basic need and the information need - adding to the complexity. According to Rouse and Rouse (1984, p. 129): "Humans seldom seek information as an end in itself. Instead, information seeking is part of the process of decision making, problem solving or resource allocation."

- In a later model (1996), Wilson (1999a, b) argues that people seek information to solve a problem. During the information-seeking process different levels of anxiety may be experienced at different stages. Wilson et al. (2002, p. 705) explain: "In moving through each of the stages of problem identification, problem definition, problem resolution and solution presentation, uncertainty must be reduced and individuals are seen as engaging in interaction episodes with information sources (including people and other sources, as well as information retrieval systems) to resolve their uncertainty."

Users should know that it is normal to feel anxiety, and that there are different techniques for solving the problem. These include addressing it from different angles or finding a good document as a point of departure and exploring other options from there, watching out for search terminology, or talking to experts. The complexity of analyzing information needs can be illustrated by a step-by-step demonstration of how real users can deal with their real-life information needs - starting from their first interpretation, and not the "perfect" strategy. Users should, however, also be made aware that there are many factors that will motivate them to find information to solve the problem at hand.

In 1996 Wilson (as discussed in Wilson, 1999b) presented three relevant theoretical ideas to explain motivation, namely stress/coping theory (which offers explanations for why some needs do not invoke information-seeking behaviour); risk/reward theory (which may help to explain which sources of information may be used more than others by a given individual); social-learning theory (which embodies the concept of self-efficacy, and the idea of conviction or that one can successfully execute the behaviour required to produce the desired outcomes). 
Information needs have also been linked to tasks and task performance. Vakkari (2003) offers an extensive review of the literature on tasks and information searching. According to Bilal (2000, 2001, 2002), Byström and Järvelin (1995) and Vakkari (1998, 1999, 2001), the type of task has an impact on information-seeking behaviour, how the need is seen and efforts to fulfil the information need. Users should thus be made aware that their perceptions of the task at hand will also influence their interpretation of their information needs, and probably their perseverance in finding information.

\section{Exploring the interactive and iterative nature of information seeking}

Complex information needs may consist of more than one "information need", and may often require more than one episode of information seeking (see, e.g. Bryström and Hansen, 2002, p. 246). Information seeking can be considered as iterative, cyclic processes that result in failure or success.

Different stages and moves have been identified in information seeking. Kuhlthau, (1991, 1993, 1994) refers to initiation, selection, exploration, formulation, collection and presentation, while Choo et al. (2000a, 2000b, 2000c) distinguish starting, chaining, browsing, differentiating, monitoring and extracting. Some information seekers (representing different disciplines or occupations) have shown a change in their preference for information channels depending on their phase of information seeking (Ellis, 1989; Ellis et al., 1993; Ellis and Haughan, 1997).

Users should realise that it is "normal" for information needs to change and evolve during the process of information seeking. It is "normal”, and to be expected, that you should change your mind about the relevance of documents and what information you actually require. This might mean that you have to repeat a search through different search engines or databases, or follow a different strategy. Spink (1997), Spink et al. (1999) and Cosijn and Ingwersen (2000) deal with different aspects of relevance judgment. A search may also be repeated over different days, or even weeks, as understanding of the problem at hand and its complexities develop. The documents and information used may lead to new insights into the problem, and resources to follow up on, for example searching for specific titles, conferences or authors. It is essential for users to understand that research has shown that information seeking is often not a once-off process. Spink et al. (1999, 2002a, b, c) refer to successive searching and multitasking. Much also depends on evolving cognitive structures, personality, learning styles, etc.

\section{Exploring the power of different types of information searching}

In the early days of traditional online searching, analytical searching, very careful planning of search strategies and the correct application of search techniques were stressed. Analytical searches are appropriate when you know what you are looking for and if you are confident about your choice of search terms. They are still important for cost-effective searching and when using expensive commercial information services. The 
power of browsing search techniques (e.g. as explained by Marchionini, 1985) when unsure about an information need, search concepts or search terms should however, not be underestimated. Browsing the web site of a cancer association may for instance lead to nutritional information, which may lead to the search term "neutropenic diet" which is information required by patients who have had a stem cell transplant to treat leukaemia. Browsing can also be applied when doing a general search on a database such as Cancerlit, and then browsing for search terms, or a more appropriate angle to take to a topic. Choo et al. (1999, 2000a, b, c) distinguish between undirected viewing, conditioned viewing, and informal and formal searches. Each of these is done with different intentions, can add to users' insight into their information need, and should be encouraged as useful alternatives to analytical searching.

Browsing can also be an excellent approach when looking for inspiration or creative thinking and for making serendipitous finds, the value of which is strongly stressed by Foster and Ford (2003, p. 336). Serendipity refers to making happy chance findings unexpectedly finding interesting or useful information.

Searching according to known authors, working from a highly relevant document, review article or encyclopaedia chapter or following up on citations listed in relevant documents, are other excellent ways of tracing documents difficult to retrieve through analytical searching.

\section{Dealing with affective aspects of information-seeking behaviour}

Users and LIS practitioners often feel frustrated during a search and even more so when they turn up information that makes them insecure and even anxious rather than confident about their ability to solve a problem. Research by Khulthau $(1991,1993,1994)$ and others has shown that these are very common feelings which are actually part of learning experiences as explored in learning theories. Kuhlthau reports on the feelings, actions and thoughts involved. Information often leads to new questions, and uncertainty about whether the information is reliable or sufficient to solve the problem. Often users find that if they continue with the search and explore different or new options, they get to a point where they feel confident again. If LIS practitioners share such experiences with users, it might be easier for them to persist in their search "battles". LIS practitioners must realise that information seeking is not just a cognitive process, but also has a very strong affective dimension that can impact on the search success. They must share these insights with users. 


\section{Acknowledging and dealing with barriers to successful information seeking}

Many factors (also called variables or barriers) may influence information-seeking behaviour and have been empirically tested or acknowledged in information-seeking studies. These include occupations, task complexity, cognitive styles, individual characteristics, the information seeker's experience with the WWW, information retrieval systems and information seeking, research skills, the ethos and work patterns of different institutions in different countries, the conceptual understanding of a topic, computer literacy, the intuitiveness of the IRS, experience with the specific WWW search tool, training received, understanding and interpretation of the information need(s), the discipline in which the information seeker works, the information seeker's existing state of knowledge of the problem area, psychological factors, demographic factors, rolerelated factors, gender, age, interpersonal factors, personal factors, user characteristics, the environment, source characteristics, the information seeker's perception of the nature of the problem and many more (Bruce, 1999; Bryström, 2002; Bryström and Järvelin, 1995; Kim and Allen, 2002; Large et al., 2002; Lazonder et al., 2000; Pennanen and Vakkari, 2002; Schamber, 2000; Wilson, 1999a; Wilson et al., 2002).

If users have a better understanding of factors that may impact on the success of their information seeking, it might be easier for them to deal with lesser levels of success and motivate them to find solutions (e.g. using online vocabulary tools such as dictionaries and thesauri to overcome vocabulary problems). Some barriers such as inadequate computer skills can be addressed through intervening measures by users or LIS practitioners. Other barriers such as access to the web, funds to search commercial databases, availability of information on particular topics are, however, more or less outside their sphere of control. Such barriers are not necessarily static, however, and should be monitored for changes on an ongoing basis.

\section{Using an intermediary}

Ingwersen's (1992) cognitive model makes provision for the actions of an intermediary. Users should realize what intermediaries can do for them, and when to seek their advice. LIS professionals should take special note of the process of mediated information retrieval during human information-seeking processes to characterize aspects of this process, including the information seekers' changing situational context, information problems, uncertainty reduction, successive searching, cognitive styles and cognitive and affective states (Ford et al., 2002b; Spink et al., 2002a, b; Wilson et al., 2002; Ellis et al., 2002).

\section{Understanding the environment}

Users should be made aware of the impact their environment may have on information seeking behaviour. Wilson (1981) distinguishes work, organisational, socio-cultural, politico-economic, and physical environments. He also refers to the impact of the work 
role and job performance, which can be considered to be the immediate environment. Every work environment has a particular climate, and there may also be reference groups in the work environment with which the information seeker associates. Spink and Cole (2001, p. 302) refer to such circumstances or environments as microcultures and small worlds. Users must be alerted to the potential impact of their environments, and consider ways to deal with these if necessary.

\section{Better information-seeking structures}

Spink and Cole (2004, p. 767) argue that: "While there may be company mechanisms in place to aid such information seeking, and to make it more efficient, if better informationseeking structures were in place, not only would workers waste less time in informational pursuits, but they would also find things, discover new processes, etc., that would benefit the corporation's bottom line.”

If we wish to stress successful, productive and creative use of information and knowledge generation, we should move from the formulation of search strategies and correct application of system techniques to exploiting the full spectrum of the available information infrastructure. Users need to be aware of the very extensive range of information channels and resources, and where and how each fits in (e.g. books [webbased OPAC], journal articles available through commercial databases such as Dialog or fulltext databases such as those available through Emerald and ScienceDirect). Apart from commercial services available through LIS services, free services should be brought to users' attention, for example the Medline and ERIC databases available through the web. If Google and Yahoo cannot find the required information, where else can users identify suitable search engines or directories? Danny Sullivan's SearchEngine Watch (www.searchenginewatch.com) can be recommended as a point of departure for identifying useful information channels. Users can also be directed to subject specific portals.

Researchers have found that users tend not to use a variety of information channels, that there are a number of factors that influence their choice of information channels and that there are certain stages in projects at which they prefer particular channels (e.g. Choo et al., 1999, 2000a, b, c; Ellis et al., 1993; Ellis and Haughan, 1997). LIS practitioners should take note of the relevancy of such findings for their particular user group, and should also ask questions like:

- How can we support users by saving them time and effort in identifying appropriate information channels? Portals can be useful, but their use and users' navigation behaviour should be monitored (e.g. through transaction log analysis).

- How can we bring the full spectrum of information channels (commercial as well as free) to users' attention?

- How can we make it easier for users to get access to full-text documents?

- How can we motivate users to find the best possible solution to the problem at hand by searching a wider selection of information channels? 
Users should realise that it is acceptable and even advisable to move between different information channels and that they need to understand what different channels offer.

\section{Linking information seeking, information use and knowledge generation}

The actual use and communication of information is seldom part of information seeking models. Kulthau (1991) and Ellis and Haughan (1997) mention information use, but do not deal with it in detail. Hirsh and Dinkelacker (2004) is one of the few studies actually linking information seeking to the production of information at the Hewlett Packard Labs. Users should also be encouraged to consider how they want to use the information. Nicholas and Dobrowolski (1999, p. 232) for example state that "looking for personal inspiration will become more important than looking for what is now called information”.

Criticism of IR research methodology, theory development and the lack of progress is common and may prevent LIS practitioners from getting involved in research. There is, however, a dire need for more practical, real-life action research.

The following research approaches for practitioners can be distinguished:

- Research according to IR research protocol and methodology as reflected in the many research articles (reviewed by Jansen and Pooch, 2001; Hsieh-Yee, 2001 and Fourie, 2002, 2004). This can include research linked to formal postgraduate qualifications or for research grants, but may be too time consuming and complex for practitioners who must focus on offering a service.

- Informal, small-scale studies to get a better understanding of users and a specific situation. Such studies can be very useful in shedding light on particular circumstances, but it would not be possible to generalize research findings.

- Collaborative research with academics that supports the application of research methodology and theoretical frameworks. This might perhaps be the best approach to benefit both practitioners and academic researchers.

LIS practitioners interested in small-scale projects could consider the following:

- encouraging end-users to share their true information-seeking experiences;

- $\quad$ analysing information-seeking behaviour from different perspectives.

There are a number or other aspects that will not be discussed as part of this article, for example reconsidering the meaning attached to relevance, and learning from information seeking models and IR research. 


\section{Sharing experiences and perspectives}

Once LIS practitioners and users understand the value of learning from users' experiences, it should be easier to encourage users to share their experiences. Based on these, theoretical models of web information-seeking behaviour can be built. Experiences can be shared through interviews, focus group interviews, informal conversations, observations and narratives (Bates, 2004). It would also be good to share the best practices of LIS practitioners and subject experts. Such sharing should happen on an ongoing basis and interventions planned accordingly.

Paradigms are the views we take on a research situation and the way we look at the research situation. Researchers can work from a specific paradigm such as the systems or cognitive paradigm, or they can combine insights from different paradigms. The important thing is for researchers to note the impact different views will have on the data they collect and their research results. It has often been pointed out that IR research and web information-seeking studies can benefit from insights from other disciplines. Limberg (2000) argues for the value of phenomenography, while Kuhlthau (following a phenomological approach) acknowledges insights from Dewey, Bruner and Kelly (Kuhlthau, 1991). Kelly's personal construct theory is also acknowledged by Crudge and Johnson (2004). Wilson (1999b) favors input from communication behaviour: he is of the opinion that we can also draw from fields such as the cognitive sciences, decision making, psychology, innovation, health communication and consumer research, risk/reward theory, social learning theory and self-efficacy theory. Hjørland (1997) refers to the impact of activity, while Sánchez-Franco and Rodríguez-Bobada Rey (2004) build on Csikszentmihalyi's flow theory. Ford (2004) considers the intellectual processes in information seeking that are aimed at the resolution of some problematic situation. He uses Pask's conversation theory in developing tentative theories through information seeking. Joinson and Banyard (2002) discuss psychological aspects of internet information seeking - there is even talk of cyber psychology. LIS practitioners can use these research reports to conduct studies from their own fields of interest or subjects majored in, and in such a way bring new perspectives to our understanding of web information seeking.

\section{Conclusion}

There is much that LIS practitioners can learn from the research literature on web information-seeking studies. In order to be of value the findings should be made more accessible to practitioners in terms of the channels through which the research is communicated, the language of discussion, and the explicitness about how the findings can be used to change web information-seeking practice. This article has made a few suggestions in this regard. There are, however, many more findings to consider in practice. 


\section{References}

Bates, J.A. (2004), "Use of narrative interviewing in everyday information behavior research", Library and Information Science Research, Vol. 26 No.1, pp.15-28.

Belkin, N.J., Oddy, R.N., Brooks, H.M. (1982a), "ASK for information retrieval. Part I", Journal of Documentation, Vol. 38 No.2, pp.61-71.

Belkin, N.J., Oddy, R.N., Brooks, H.M. (1982b), "ASK for information retrieval. Part II", Journal of Documentation, Vol. 38 No.3, pp.575-91.

Bilal, D. (2000), "Children's use of the Yahooligans! web search engine. Part 1. Cognitive, physical, and affective behaviors on fact-based search tasks", Journal of the American Society for Information Science, Vol. 51 No.7, pp.646-65.

Bilal, D. (2001), "Children's use of the Yahooligans! web search engine. Part 2. Cognitive and physical behaviors on complex research tasks", Journal of the American Society for Information Science, Vol. 52 No.2, pp.118-36.

Bilal, D. (2002), "Perspective on children's navigation of the worldwide web: does the type of search task make a difference?", Online Information Review, Vol. 26 No.2, pp.108-17.

Bilal, D., Kirby, J. (2002), "Differences and similarities in information seeking: children and adults as web users", Information Processing and Management, Vol. 38 No.4, pp.649-70.

Bruce, H. (1999), "Perceptions of the internet: what people think when they search the internet for information", Internet Research: Electronic Networking Applications and Policy, Vol. 9 No.3, pp.187-99.

Burwell, L.A. (2001), "Too old to surf? No way! An internet course for seniors", American Libraries, Vol. 32 No.10, pp.40.

Byström, K. (2002), "Information and information sources in tasks of varying complexity", Journal of the American Society for Information Science and Technology, Vol. 53 No.7, pp.581-91.

Byström, K., Hansen, P. (2002), "Work tasks as units for analysis in information seeking and retrieval studies", in Bruce, H., Fider, R., Ingwersen, P., Vakkari, P.

(Eds),Proceedings of the 4th International Conference on Conceptions of Library and Information Science: Emerging Frameworks and Methods, 21-25 July 2002, Greenwood Village, CO, pp.239-51.

Byström, K., Järvelin, K. (1995), "Task complexity affects information seeking and use", Information Processing and Management, Vol. 31 No.2, pp.191-213. 
Carey, R.F., McKechnie, L.E.F., McKenzie, P.J. (2001), "Gaining access to everyday life information seeking", Library and Information Science Research, Vol. 23 No.2, pp.31934.

Chatman, E. (1991), "Life in a small world: applicability of gratification theory to information seeking behaviour", Journal of the American Society for Information Science, Vol. 42 No.3, pp.438-49.

Choo, C.W., Detlor, B., Turnbull, D. (1999), “Information seeking on the web: an integrated model of browsing and searching”, ASIS Annual Meeting, available at: http://0-choo.fis.utoronto.ca.innopac.up.ac.za:80/fis/respub/asis99/ (accessed 14 March 2002).

Choo, C.W., Detlor, B., Turnbull, D. (2000a), "Information seeking on the web: an integrated model of browsing and searching", First Monday, available at:

http://firstmonday.org/issues/issuess_2/choo/ index.html (accessed 2 August 2002), Vol. 5 No. 2 .

Choo, C.W., Detlor, B., Turnbull, D. (2000b), "Working on the web: an empirical model of web use”, paper presented at the HICSS 33 (Hawaii International Conference on Systems Science), 4-7 January, available at: http://0choo.fis.utoronto.ca.innopac.up.ac.za:80/fis/respub/HICSS/default.html/ (accessed 14 March 2002).

Choo, C.W., Detlor, B., Turnbull, D. (2000c), Web Work: Information Seeking and Knowledge Work on the World Wide Web, Kluwer Academic, Dordrecht.

Cool, C. (1996), "Information seeking behaviour in new searching environments", in Ingwersen, P., Porse, N.O. (Eds),Proceedings of the 2nd International Conference on Conceptions of Library and Information Science: Integration in Perspective, 13-16 October 1996, Copenhagen, Royal School of Librarianship, pp.403-16.

Cooper, L.Z. (2002), "A case study of information-seeking behavior in 7-year old children in a semi-structured situation", Journal of the American Society for Information Science and Technology, Vol. 53 No.11, pp.904-22.

Cosijn, E., Ingwersen, P. (2000), "Dimensions of relevance", Information Processing and Management, Vol. 26 No.4, pp.533-50.

Crudge, S.E., Johnson, F.C. (2004), "Using the information seeker to elicit construct models for search engine evaluation", Journal of the American Society for Information Science and Technology, Vol. 55 No.9, pp.793-806. 
Dervin, B. (1999), "On studying information seeking methodologically: the implications of connecting metatheory to method", Information Processing and Management, Vol. 34 No.6, pp.727-50.

Dervin, B., Nilan, M. (1986), "Information needs and uses", in Williams, M.E. (Eds),Annual Review of Information Science and Technology, Knowledge Industry Publications, White Plains, NY, Vol. Vol. 21 pp.3-33.

Ellis, D. (1989), "A behavioural approach to information retrieval design", Journal of Documentation, Vol. 46 No.3, pp.318-38.

Ellis, D. (1990), New Horizons in Information Retrieval, Library Association, London.

Ellis, D. (2002), "Information seeking and mediated searching. Part 5: User-intermediary interaction", Journal of the American Society for Information Science and Technology, Vol. 53 No.11, pp.883-93.

Ellis, D., Haughan, M. (1997), "Modeling the information seeking patterns of engineers and research scientists in the industrial environment", Journal of Documentation, Vol. 54 No.4, pp.384-403.

Ellis, D., Cox, D., Hall, K. (1993), "A comparison of the information seeking patterns of researchers in the physical and social sciences", Journal of Documentation, Vol. 49 No.4, pp.356-69.

Ford, N. (2002), "Information seeking and mediated searching. Part 4: Cognitive styles in information seeking", Journal of the American Society for Information Science and Technology, Vol. 53 No.9, pp.728-35.

Ford, N. (2004), "Modelling cognitive processes in information seeking: from Popper to Pask", Journal of the American Society for Information Science and Technology, Vol. 55 No.9, pp.769-82.

Ford, N., Miller, D., Moss, N. (2002), "Web search strategies and retrieval effectiveness: an empirical study", Journal of Documentation, Vol. 58 No.1, pp.30-48.

Ford, N., Miller, D., Moss, N. (2003), "Web search strategies and approaches to studying", Journal of the American Society for Information Science and Technology, Vol. 54 No.6, pp.473-89.

Foster, A., Ford, N. (2003), "Serendipity and information seeking: an empirical study", Journal of Documentation, Vol. 59 No.3, pp.321-40.

Fourie, I. (2002), "A review of web information-seeking/searching studies (2000-2002): implications for research in the South African context", in Bothma, T., Kaniki, A. 
(Eds),Progress in Library and Information Science in Southern Africa (ProLISSA), Infuse, Pretoria, pp.49-76.

Fourie, I. (2004), "A theoretical model for studies on web information-seeking behaviour: how to look and what we might see", in Bothma, T., Kaniki, A. (Eds),Progress in Library and Information Science in Southern Africa (ProLISSA), Infuse, Pretoria, pp.69-97.

Hansen, P., Järvelin, K. (2005), "Collaborative information retrieval in an informationintensive domain", Information Processing and Management, Vol. 41 No.8, pp.1101-19.

Heinström, J. (2000), "The impact of personality and approaches to learning on information behaviour", Information Research, available at: http://informationr.net/ir/53/paper78.html (accessed 7 February 2005), Vol. 5 No.3.

Hirsh, S., Dinkelacker, J. (2004), "Seeking information in order to produce information: an empirical study at Hewlett Packard Labs", Journal of the American Society for Information Science and Technology, Vol. 55 No.9, pp.807-17.

Hjørland, B. (1997), Information Seeking and Subject Representation: An Activitytheoretical Approach to Information Science, Greenwood Press, Westport, CT.

Hsieh-Yee, I. (2001), "Research on web search behaviour", Library and Information Science Research, Vol. 23 No.1, pp.167-85.

Hyldegård, J. (2004), "Collaborative information behaviour - exploring Kuhlthau's information search process model in a group-based educational setting", Information Processing and Management, Vol. 42 No.1, pp.276-98.

Ingwersen, P. (1992), Information Retrieval Interaction, Taylor Graham, London.

Ingwersen, P. (1996), "Cognitive perspectives of information retrieval interaction: elements of a cognitive IR theory", Journal of Documentation, Vol. 52 No.1, pp.3-50.

Ingwersen, P. (1999), "Cognitive information retrieval", Annual Review of Information Science and Technology, Vol. 34 No.1, pp.3-52.

Jansen, B.J., Pooch, U. (2001), "A review of web searching studies and a framework for future research", Journal of the American Society for Information Science and Technology, Vol. 52 No.3, pp.235-46.

Joinson, A., Banyard, P. (2002), "Psychological aspects of information seeking on the internet", Aslib Proceedings, Vol. 54 No.2, pp.95-102.

Kerka, S. (1998), Learning Styles and Electronic Information: Trends and Issues Alert, available at: www.cete.org/acve/textonly/docgen.asp?tbl=tiaandID=12. 
Kim, K-S., Allen, B. (2002), "Cognitive and task influences on web searching behavior", Journal of the American Society for Information Science and Technology, Vol. 53 No.2, pp.109-19.

Kuhlthau, C.C. (1991), "Inside the search process: information seeking from the users' perspective", Journal of the American Society for Information Science, Vol. 42 No.5, pp.361-71.

Kuhlthau, C.C. (1993), "A principle of uncertainty for information seeking", Journal of Documentation, Vol. 49 No.4, pp.339-55.

Kuhlthau, C.C. (1994), Seeking Meaning: A Process Approach to Library and Information Services, Ablex, Norwood, NJ.

Large, A., Beheshti, J., Rahman, T. (2002), "Gender differences in collaborative web searching behavior: an elementary school study", Information Processing and Management, Vol. 38 No.3, pp.427-43.

Lazonder, A.W., Biemans, H.J.A., Wopereis, I.G.J.H. (2000), "Differences between novice and experienced users in searching information on the worldwide web", Journal of the American Society for Information Science, Vol. 51 No.6, pp.576-81.

Lee, Y-J. (2005), "VisSearch: a collaborative web searching environment", Computers and Education, Vol. 44 No.3, pp.423-39.

Limberg, L. (1999), "Experiencing information seeking and learning: a study of the interaction between two phenomena", Information Research, available at http://informationr.net/ir/5-1/paper68.html, Vol. 5 No.1.

Limberg, L. (2000), "Phenomenography: a relational approach to research on information needs, seeking and use", The New Review of Information Behavior Research, Vol. 1 No.1, pp.51-67.

Marchionini, G. (1995), Information Seeking in Electronic Environments, Cambridge University Press, Cambridge.

Nahl, D., Tenopir, C. (1996), "Affective and cognitive searching behavior of novice endusers of a full-text database", Journal of the American Society for Information Science, Vol. 47 No.4, pp.276-86.

Nicholas, S., Dobrowolski, T. (1999), "The tail wags the dog: the future of information is now", in Scammel, A.A. (Eds),I in the Sky: Visions of the Information Future, Aslib, London. 
Nicholas, S., Huntington, P., Williams, P., Dobrowolski, T. (2004), "Re-appraising of information seeking behaviour in a digital environment: bouncers, checkers, returnees and the like", Journal of Documentation, Vol. 60 No.1, pp.24-43.

Ozmutlu, S., Spink, A., Ozmutlu, H.C. (2004), "A day in the life of web searching: an exploratory study", Information Processing and Management, Vol. 40 No.2, pp.319-45.

Pennanen, M., Vakkari, P. (2002), "Student's cognition and information searching while preparing a research proposal", in Bruce, H., Fidel, R., Ingwersen, P., Vakkoni, P. (Eds),Proceedings of the 4th International Conference on Conceptions of Library and Information Science: Emerging Frameworks and Methods, Greenwood Village, CO, 2125 July 2002, pp.33-48.

Pettigrew, K.E., Durrance, J.C., Unruh, K.T. (2002), "Facilitating community information seeking using the internet: findings from three public library-community network systems", Journal of the American Society for Information Science and Technology, Vol. 53 No.11, pp.894-903.

Pharo, N., Järvelin, K. (2004), "The SST method: a tool for analysing web information search processes", Information Processing and Management, Vol. 40 No.4, pp.633-54.

Ren, W.-H. (2000), "Library instruction and college student self-sufficiency in electronic information searching", Journal of Academic Librarianship, Vol. 26 No.5, pp.323-8.

Rouse, W.B., Rouse, S.H. (1984), "Human information seeking and design of information systems", Information Processing and Management, Vol. 20 No.1\&2, pp.129-38.

Sánchez-Franco, M.J., Rodríguez-Bobada, R.J. (2004), "Personal factors affecting users' web session lengths", Internet Research: Electronic Network Applications and Policy, Vol. 14 No.1, pp.62-80.

Savolainen, R. (1995), "Everyday life information seeking: approaching information seeking in the context of way of life", Library and Information Science Research, Vol. 17 No.2, pp.259-84.

Schamber, L. (2000), "Time-line interviews and inductive content analysis: their effectiveness for exploring cognitive behaviors", Journal of the American Society for Information Science, Vol. 51 No.8, pp.734-44.

Spink, A. (1997), "Study of interactive feedback during mediated information retrieval", Journal of the American Society for Information Science, Vol. 48 No.5, pp.382-94.

Spink, A. (2002a), "Information-seeking and mediated searching. Part 1: Theoretical framework and research design", Journal of the American Society for Information Science and Technology, Vol. 53 No.9, pp.695-703. 
Spink, A. (2002b), "Information-seeking and mediated searching. Part 3: Successive searching", Journal of the American Society for Information Science and Technology, Vol. 53 No.9, pp.716-27.

Spink, A., Cole, C. (2001), "Introduction to the special issue: everyday life informationseeking research", Library and Information Science Research, Vol. 23 No.2, pp.301-4.

Spink, A., Cole, C. (2004), "Introduction", Journal of the American Society for Information Science and Technology, Vol. 55 No.9, pp.767-8.

Spink, A., Bateman, J., Greisdorf, H. (1999), "Successive searching behaviour during information seeking: an exploratory study", Journal of Information Science, Vol. 25 No.3, pp.439-49.

Spink, A., Ozmutlu, H.C., Lorence, D.P. (2004), "Web searching for sexual information: an exploratory study", Information Processing and Management, Vol. 40 No.1, pp.11323.

Spink, A., Ozmutlu, H.C., Ozmutlu, S. (2002), "Multitasking information seeking and searching processes", Journal of the American Society for Information Science and Technology, Vol. 53 No.8, pp.639-52.

Vakkari, P. (1998), "Growth of theories on information seeking: an analysis of growth of a theoretical research program on the relation between task complexity and information seeking", Information Processing and Management, Vol. 34 No.2 \& 3, pp.361-82.

Vakkari, P. (1999), "Task complexity, problem structure and information actions: integrating studies on information seeking and retrieval", Information Processing and Management, Vol. 35 No.7, pp.819-37.

Vakkari, P. (2001), "A theory of the task-based information retrieval process: a summary and generalization of a longitudinal study", Journal of Documentation, Vol. 57 No.1, pp.44-60.

Vakkari, P. (2003), "Task-based information searching", in Cronin, B. (Eds),Annual Review of Information Science and Technology, Information Today, Medford, NJ, pp.413-64.

Waldman, M. (2003), "Freshmen's use of library electronic resources and self-efficacy", Information Research, available at http://informationr.net/ir/8-2/infres82.html (accessed 7 February 2005), Vol. 8 No.2, .

Whitmere, E. (2004), "The relationship between undergraduates' epistemological beliefs, reflective judgment, and their information-seeking behavior", Information Processing and Management, Vol. 40 No.1, pp.97-111. 
Wilson, T.D. (1981), "On user studies and information needs", Journal of Librarianship, available at: http://informationr.net/tdw/publ/papers/1981infoneeds.html, Vol. 37 No.1, pp.3-15.

Wilson, T.D. (1999a), "Exploring models of information behaviour: the uncertainty project", Information Processing and Management, Vol. 35 No.6, pp.839-49.

Wilson, T.D. (1999b), "Models in information behaviour research", Journal of Documentation, Vol. 55 No.3, pp.249-70.

Wilson, T.D. (2002), "Information seeking and mediated searching. Part 2: Uncertainty and its correlates", Journal of the American Society for Information Science and Technology, Vol. 53 No.9, pp.704-15.

\section{About the author}

Dr Ina Fourie is an Associate Professor in the Department of Information Science at the University of Pretoria, South Africa. She teaches aspects of information organisation and retrieval at undergraduate and postgraduate level. Her research interests include information seeking behaviour, current awareness services, instructional design, and distance and telematic teaching. She is a member of CILIP, UKOLUG, ASIS \& T, and a number of local associations. Dr Ina Fourie is the corresponding author and can be contacted at: fouriei@postino.up.ac.za 